
\title{
25 Research Soure \\ Ethnobotanical Study of Fumaria Indica Plant From the Hilly and Plain Areas of Haripur
}

\author{
Lubna Shaeen \\ Hazara University \\ Gulam Mujtaba Shah \\ hazara university \\ Nadia Rehman \\ Hazara University \\ saira bibi ( $\nabla$ sairabibi333@hu.edu.pk) \\ Women University Swabi \\ fiaz khan \\ Hazara University \\ Waseem Ahmad \\ University of Haripur \\ Shah Masaud Khan \\ University of Haripur
}

Research

Keywords: ethno medicinal survy, hilly areas, plain areas

Posted Date: July 22nd, 2020

DOI: https://doi.org/10.21203/rs.3.rs-44098/v1

License: (c) (i) This work is licensed under a Creative Commons Attribution 4.0 International License.

Read Full License 


\section{Ethnobotanical study of Fumaria indica plant from the hilly and plain areas of Haripur}

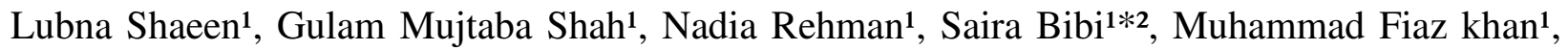
Waseem Ahmad ${ }^{1}$, Shah Masaud Khan ${ }^{1}$ 


\title{
Ethnobotanical study of Fumaria indica plant from the hilly and plain areas of Haripur
}

\begin{abstract}
Background: the purpose of this study was to find out the ethnobotanical use of Fumaria indica plant from the hilly and plain areas of Haripur . Methods:The plant samples of leaf, flowers and root were collected from two hilly areas (Srikot, Khanpur) and two plane areas (Haripur city, Tarbela) of District Haripur and processed for further analysis process. The preferences of local people for the treatment of various ailments in terms of medicinal plant used, part used, the category of diseases treated and the form of therapeutic use (recipe) were analyzed with the help of a questionnaire survey. The recorded data was tabulated theme wise and Microsoft Excel program was used in the calculation of values and percent references and its presentation in graphic form. Results: Ethnobotanical study showed that the Fumaria indica plant used as a source of medicine in local community, the powder form was used in allergies, fevers and diabetes. The plant was used as a source of medicine and cure many types of bacteria diseases. conclusion : Fumaria indica \& Caesalpinia bonducella are the plants known for their digestive, spasmolytic, diuretic, anthelmintic, hepatoprotective, anti-inflammatory, antipyretic anti dysentery activity.Powder drugs of (leaves, roots and flowers) of Fumaria indica were made for different analyses.
\end{abstract}

Keywords: ethno medicinal survy,hilly areas , plain areas 


\section{Introduction}

Fumariaceae is a small family of flowering plants likely to contain about 14 genera and nearly about 400 species were found in Pakistan (Mabberley, 1987). The medicinal importance of Fumariaceae is well-know and had great values. The Fumaria indica of the family Fumariaceae are used in medicine for curing snake bite and having phytochemical constituents like alkaloids, tannins, triterpenoids, steroids which has huge medicinal valued (Rao et al., 2009). The species of the family are used traditionally in Pakistan and India has great medicinal valued used for cured Allergy traditionally medicine as blood purifier, laxative, antiemetic, cholagogue, sedative and gastrointestinal disorder, also used for the cure of temperature (Maiza-Benabdesselam et al., 2007).Fumaria indica has great medicinal importance used in the treatment of constipation, diarrhea, fevers and urinary diseases (Canales et al., 2005). Its parts are being used for skin diseases, shoot are in dried form used as herbal tea for relive abdominal pain (Shah and Khan, 2017). To evaluate the Fumaria indica in hilly and plane areas of Haripur and to measure the ethnomedicinal value of this herbal plant(Singh et al., 2011). F. indica have extensive medicinal utilization in the Indian conventional medicine, searches conducted to evaluate severe and chronic toxicity of a $60 \%$ ethanolic take out of $F$. indica in rodents correspondingly. In severe toxicity search used Swiss strain albino rodent of a few gender were managed verbally $F$. indica quantity of 2, 1.6 and $6 \mathrm{~g} / \mathrm{kg}$ found for behavioral alteration and death. During 30 days of management. They observed no death or abnormal behavior, in severe toxicity. Study in mice at all the three level $F$. indica did not generate any special change in body weight, daily food and water ingestion of rodents when evaluated to medium treated rats. (Kumar et al., 2018). Fumaria indica is a wildly 
growing weed found in Pakistan and many other region of the world. Fumaria also known since long to be a medicinal plant to the practitioners of Ayurvedic and Unani systems of medicine. Fumaria indica has potential health element these phytochemicals have proportion of human health benefit for curing of diseases. These chemical used as herbal medicine for the treatments of liver complaints, aches pains, diarrhea, fever, and influenza. 


\section{Material and Methods:}

\section{Ethno-botanical study}

\section{Selection of Sites}

Study on the origin of introductory investigation of the valley and conversation with stakeholders, four different locations namely Srikot and Khanpur (hilly areas), City and Tarbela dam (plane areas) were recognized and elected. These sites are different from one another on the basis of their environment particularly difference in elevation, incline, geography, surroundings, plants type and plant community. The present study is mainly base on investigation taken from the consultation with the "ancestral and local people" on the plant $(F$. indica) have cost-effective significance to them. Appropriate plants were gathered from the following study areas, recognized and conserved at the Herbarium of the Department of Botany, Hazara University Mansehra. In this study taken view of local people about the daily used of the plant which parts of the plant are used by local community were investigated. During this also tells about the local name of the plant in locally language. 


\section{Identification of Medicinally Important Plant Species.}

Local herbalists, agricultural and forest experts, local elders, and leaders were interviewed and the plant species enlisted in the first part of the study were discussed with them. Moreover, the available literature on the subject was thoroughly studied and relevant information was used to help document the plant species which were medicinally important and available in the valley.

\section{Determination of Community Preferences}

The preferences of local people for the treatment of various ailments in terms of medicinal plant used, part used, the category of diseases treated and the form of therapeutic use (recipe) were analyzed with the help of a questionnaire survey. The feedback form (as annexed in appendix 1.1) cover up the following four main areas (Ilangovan et al., 2018).

\section{Most Preferred Medicinal Plant Species.}

The responded were inviting to describe the plant name that was generally preffered by the local people for curative care. The partiality percent for the plant was analyzed through the aid of the following formula (Hussain et al., 2011).

Percent Preferences of a Species $=\frac{\text { number of respondents who termed it as most preferred speceis } * 100}{\text { Total number of respondents }}$

\section{Most preferred Type/category of ailment, cured with medicinal plants.}

The participants were inviting to mention the type of an illness by the traditional healthcare. The percent preferences for Fumaria indica were analyzed by the aid of following formula (Hussain $e t$ al., 2011).

Percent Preferences of an ailment $=\frac{\text { number of respondents who termed it as most preferred ailment } * 100}{\text { Total number of respondents }}$

\section{Most preferred type of plant part, used.}

The respondents were asked to mention the name of a plant part which was mostly preferred by the local people for traditional healthcare. The percent preference for plant part was considered through the aid of the following formula (Hussain et al., 2011). 
Percent Preferences of a plant part $=\frac{\text { number of respondents who termed it as most preferred part } * 100}{\text { Total number of respondents }}$

\subsubsection{Most preferred form of utilization (recipe).}

The responded were investigated to mention the recipe which was favored by the local people for their curative care. The percent preferences for each recipe were determine through the aid of the following formula (Ahmad and Husain, 2008).

$$
\text { Percent Preferences of a Reciepe }=\frac{\text { number of respondents who termed it as most preferred recipe } * 100}{\text { Total number of respondents }}
$$

Total one hundred (100) respondents, 25 from every site, were consulted. From each site 5 most popular villages were chosen and 5 accessible eldest participants were investigate (Khan et $a l ., 2012)$, and the data on every parameters were documented.

\section{Statistical Analysis:}

The recorded data was tabulated theme wise and Microsoft Excel program was used in the calculation of values and percent references and its presentation in graphic form.

\section{Determination of Proximate analysis of Fumaria indica}

Proximate analysis such as a (fresh, dry weight, ash, crude fiber) in Fumaria indicaplants will be determined according to the method of (Rao and Sunitha, 2011). Fresh plant was taken from the field and wash them with water for removed all dust particles from the plant moisture by the use of soft paper and weighted on scale. The plant was taken and it was freed from any sort of moisture and dust. Plant was dried in an oven at $100^{\circ} \mathrm{F}$ overnight later on the plant was cooled and weighted on scale. Plant sample was ignited in the muffle furnace at $500-600{ }^{\circ} \mathrm{C}$ for $8 \mathrm{hrs}$ and ash contents of samples were measured by AOAC (1984) method Crude fiber content was determined by taking 2 gram of plant with $4 \mathrm{ml}$ of $\mathrm{H}_{2} \mathrm{SO}_{4}$ and remains free for 30 minute after that $2 \mathrm{ml}$ Sodium hydroxide $(\mathrm{NaOH})$ were added than all samples were weighted for the absorbance of crude fiber by AOAC (1984) method. Soil pH was calculated in 1:6 soil water suspensions with a pH meter (Jackson et al., 1962).

\section{Results}




\section{Peroxidase contents}

The peroxidase content of different parts Fumaria indica in Figure 1 (a) from different locations in which the hilly area Srikot the peroxidase contents were higher $(5184 \mu \mathrm{g} / \mathrm{g})$ in the leaf extract of Fumaria indica as compare to peroxidase content $(4433 \mu \mathrm{g} / \mathrm{g})$ were found in the root extract of Fumaria indica. The peroxidase contents were lower $(3111 \mu \mathrm{g} / \mathrm{g})$ in the flower extract of Fumaria indica and from the Khanpur the peroxidase contents were higher $(7143 \mu \mathrm{g} / \mathrm{g})$ in the leaf extract of Fumaria indica as compare to peroxidase content $(5587 \mu \mathrm{g} / \mathrm{g})$ were found in the root extract of Fumaria indica. The peroxidase contents were lower $(4854 \mu \mathrm{g} / \mathrm{g})$ in the flower extract of Fumaria indica and from the plane area City peroxidase contents were higher $(10638 \mu \mathrm{g} / \mathrm{g})$ in the flower extract of Fumaria indica as compare to peroxidase contents $(7813 \mu \mathrm{g} / \mathrm{g})$ were found in the root extract of Fumaria indica. The peroxidase contents were lower $(3333 \mu \mathrm{g} / \mathrm{g})$ in the leaf extract of Fumaria indica and from Tarbela the peroxidase contents were higher $(9524 \mu \mathrm{g} / \mathrm{g})$ in the flower extract of Fumaria indica as compare to peroxidase content $(7692 \mu \mathrm{g} / \mathrm{g})$ were found in the leaf extract of Fumaria indica. The peroxidase contents were lower $(7576 \mu \mathrm{g} / \mathrm{g})$ in the root extract of Fumaria indica.

\section{Proximate analyses}

\section{Fresh weight}

The Figure 1(b) were represented that the fresh weight Fumaria indica from different locations in which hilly area Srikot fresh plant weight (5.51g) and Khanpur fresh plant weight $(5.53 \mathrm{~g})$ and from the plane area City the fresh plant weight (5.56g) were observed and from tarbela the fresh plant weight $(5.72 \mathrm{~g})$ were observed in the Fumaria indica plant. 


\section{Dry weight}

The Figure 1(c) were represented that the dry weight Fumaria indica from different locations in which hilly area Srikot dry plant weight (1.25g) and from Khanpur dry weight $(1.22 \mathrm{~g})$ and from the plane area City the dry plant weight $(1.28 \mathrm{~g})$ were observed and from Tarbela the dry plant weight $(1.24 \mathrm{~g})$ were observed in the Fumaria indica plant.

\section{Ash contents}

The data regarding ash content of Fumaria indica were showed in Figure 1(d) represent that the ash content Fumaria indica from different locations in which hilly area Srikot ash content $(0.48 \%)$ and Khanpur ash content $(0.52 \%)$ and from the plane area City ash content $(0.43 \%)$ were observed and from tarbela the ash content $(0.45 \%)$ were observed in the Fumaria indica plant.

\section{Crude fiber}

The crude fiber of different plant samples of Fumaria indica were presented in figure 1(e) the results indicated that there was a wide range of variation in the crude fiber concentration of different plant samples which are collected from different areas. From the hilly areas Srikot the crude fiber content was higher $(10.5 \mathrm{mg})$ in the root extract of Fumaria indica as compare to leaf extract $(9.8 \mathrm{mg})$ and the lower content of crude fiber $(7.1 \mathrm{mg})$ was recorded in the flower extract of Fumaria indica and Khanpur the crude fiber was higher $(10.9 \mathrm{mg})$ in the root extract of Fumaria indica as compare to leaf extract $(6.9 \mathrm{mg})$ and the lower content of crude fiber $(5.5 \mathrm{mg})$ was recorded in the flower extract of Fumaria indica. From the plane area City the crude fiber content was higher $(16.1 \mathrm{mg})$ in the leaf extract of Fumaria indica were observed as compare to the root extract $(14.5 \mathrm{mg})$ and the lower contents of crude fiber $(6.9 \mathrm{mg})$ was recorded in the flower extract of Fumaria indica and from Tarbela the crude fiber contents was higher $(10.7 \mathrm{mg})$ in the leaf extract of Fumaria indica as compare to the flower extract $(10.3 \mathrm{mg})$ were observed and the lower content $(8.1 \mathrm{mg})$ was recorded in the root extract of Fumaria indica. 


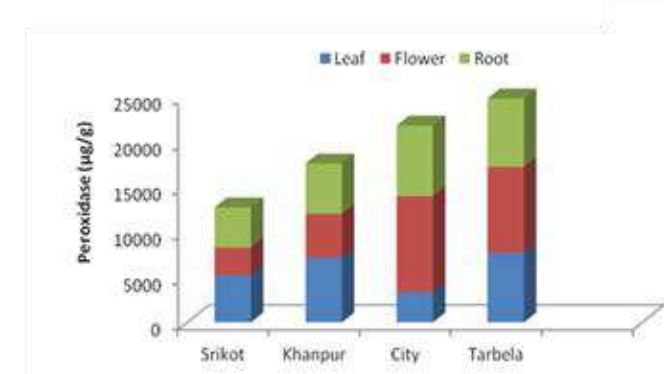

(a)

Dry weight

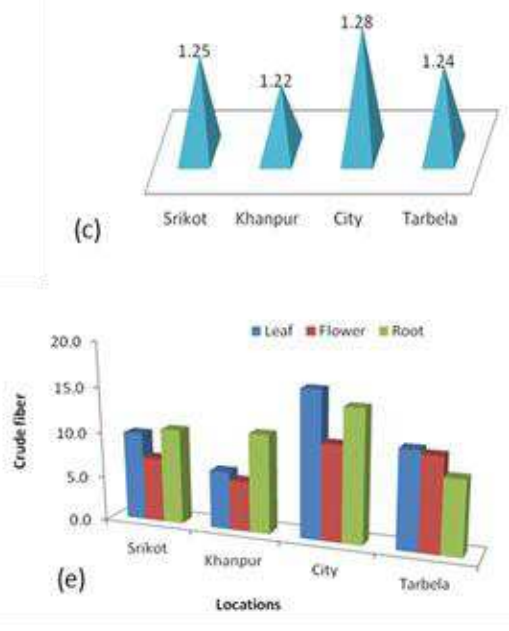

Fresh weight

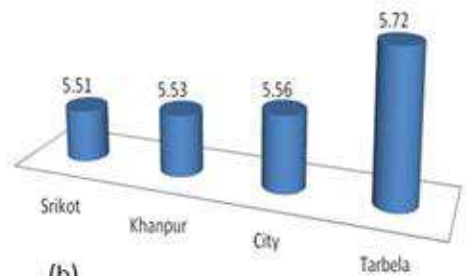

(b)

Ash value (d)

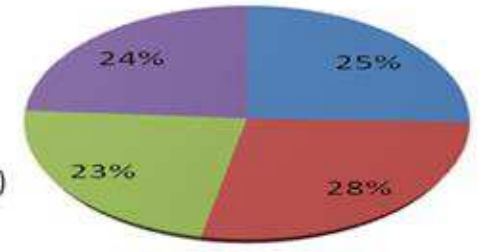
- teat = Frower $=$ Rroot

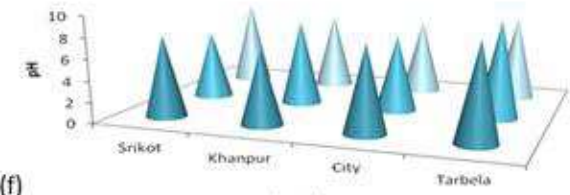

(f)

Locations

Figure 1 (a)The peroxidase contents Fumaria indica at different locationsFigure (b) Total fresh weight of Fumaria indica plant from different locationsFigure (c) Total dry weight of Fumaria indica plant from different locations. (d) The Ash content of Fumaria indica from different locations. € Crude fiber contents of Fumaria indica at different locations. (f) pH values of Fumaria indica in different parts of plant from different locations

\section{pH}

The $\mathrm{pH}$ of different plant samples of Fumaria indica were presented in figure 15.The results indicated that there was a wide range of variation in $\mathrm{pH}$ of different plant samples which are collected from different areas. From the hilly areas Srikot the $\mathrm{pH}$ was higher (7.8) in the leaf extract of Fumaria indica compare to the root extract (7.6) and the least $\mathrm{pH}$ value (6.58) was recorded in the flower extract of Fumaria indica. From Khanpur the $\mathrm{pH}$ was higher (7.5) in the leaf extract of Fumaria indica compare to the flower extract (7.2) and the least $\mathrm{pH}$ value (7.1) was recorded in the root extract of Fumaria indica. From the plane area City the $\mathrm{pH}$ was higher (8.2) in the leaf extract of Fumaria indica compare to the root extract (7.4) and the least $\mathrm{pH}$ value (7.3) was recorded in the flower extract of Fumaria indica and from Tarbela the $\mathrm{pH}$ was higher (9.1) in the 
leaf extract of Fumaria indica compare to the root extract (8.1) and the least $\mathrm{pH}$ value (7.0) was recorded in the flower extract of Fumaria indica. The $\mathrm{pH}$ value depends on the different compounds which present in the plant.

\section{Ethnobotanical study of Fumaria indica}

The Fumaria indica belong to family Fumariaceae, flowering periods (April-May) plant species were grow habit herb. Understandable reality that the public of Pakistani rural areas widely depend on plant drug for the treatment of diseases. The residents of Srikot, Khanpur, City and Tarbela valley are blessed to have wide range of wild plant that are beneficial, play vital role in environment. The results show that from these areas selected Fumaria indica were locally called (papra) and know about their medicinal importance from these selected locations.

\section{Most preferred medicinal use of Fumaria indica}

The results obtained on this factor were given in Figure 16. In terms of this study exposed that the medicinally important of species "Fumaria indica" at different locations. From the hilly area Srikot (12.21\%) and from Khanpur (13.11\%) on the other hand from plane area City (10.22\%) and from Tarbela $(11.33 \%)$ were obtained.

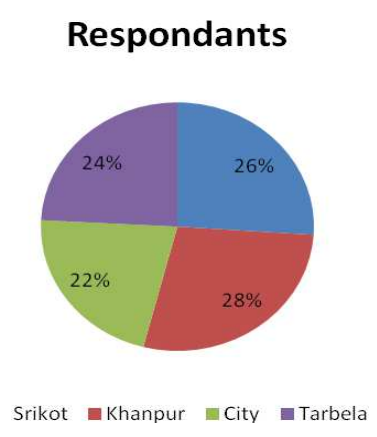

Figure 2: Percentage of respondent`s preferences for medicinal use of Fumaria indica at different locations.

\section{Most preferred Type/category of ailment, cured with Fumaria indica}

The results achieve on this factor were given in figure 17 indicates that Fumaria indica are highly medicinal value use to cured many disorders related with the digestive system (31.05\%) follow by 
those linked by respiration (6.1\%), blood purification(35.05\%), skin(18.35\%), urinary(14.43\%), nutritional and tonic (15.2\%), bones and joints $(22.05 \%)$, reproductions $(13.84 \%)$.

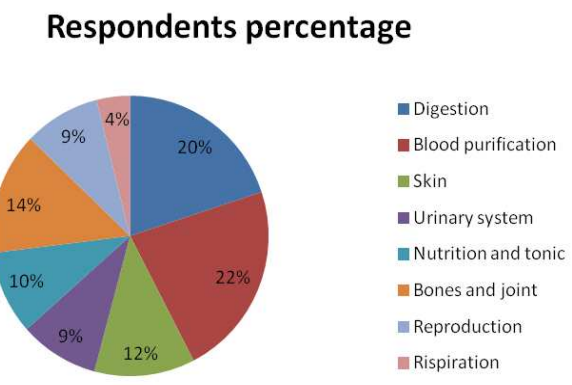

Figure 3: Percentage of respondent's preferences for category of use, of Fumaria indica from all selected locations.

Most preferred type of plant part, used

The introductory survey showed in figure 18 indicated that in maximum treatments. Whole plants (40.55\%) ,Leaves (35.05\%), Roots (15.5\%),Flowers (6.05\%) were used by the local community.

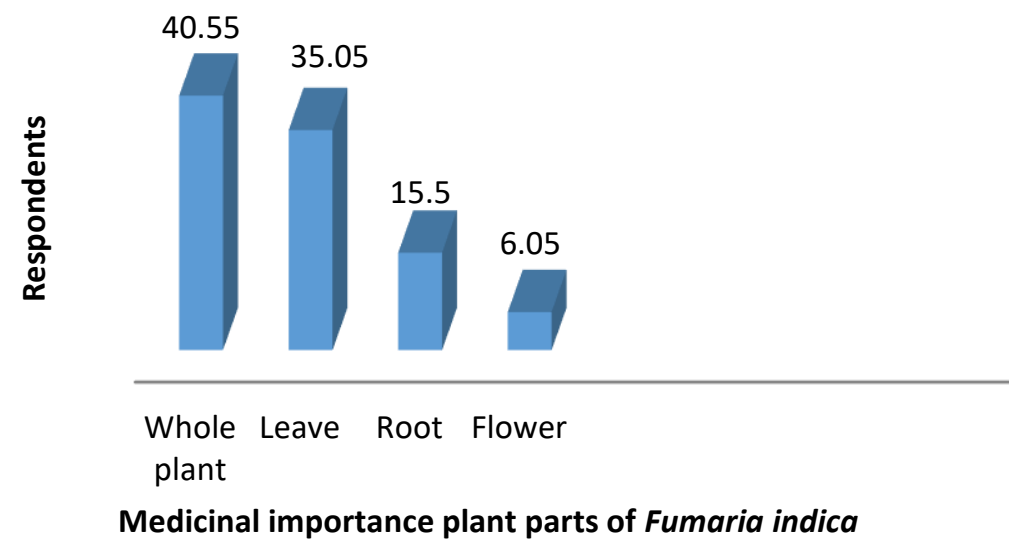

Figure 4: Percentage of respondent's preference part used of Fumaria indica at different locations. 


\section{Most preferred form of utilization (recipe)}

The four conclusion showed in figure 18 was a survey concerning the type of apply (recipe). Indicated that maximum consumption of Fumaria indica plant in the form of following. Powder (60.2\%) Decoction (30.05\%) Tea (25.5\%) Paste (15.5\%)Fresh (27.22\%) Juice (21.05\%) Cooked (3.1\%) Cream (18.05\%) Tincture (4.31\%) The results of this study indicated that powder form followed by decoction was the mainly favored the consumption by the local native community of Srikot, Khanpur, City and Tarbela in their daily life.

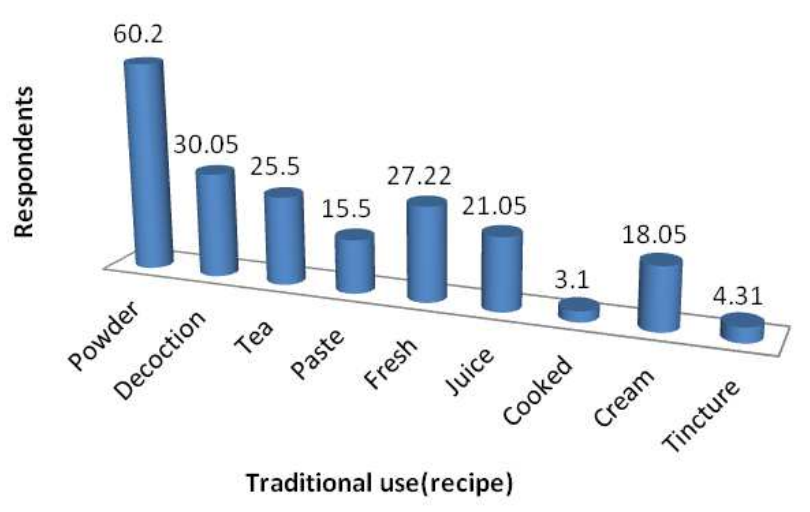

Figure 5: Percentage of respondent's preference for traditional use (recipe) of Fumaria indica at different locations.

Major Themes:

Most used /preferred local medicinal plant species.

Local name of the species: Uses in the Area:Which part is collected:

Most preferred health problem treated with local plants.

Health problems related to: Reproduction, skin, digestion, nutrition and tonic, respiration, blood purification, bones and joints, brain and nerves, urinary system.

Most preferred traditional use / recipe commonly used Tea, paste, fresh, cream, tincture, powder, and decoction, juice, cooked.

Most preferred plant part used in traditional healthcare. Flower, shoot, root, rhizome, leaves, fruit, whole plant, bark, seed 
The linear standard curved of SOD, CAT and POX in different parts Fumaria indica from different locations were represented in following figures.
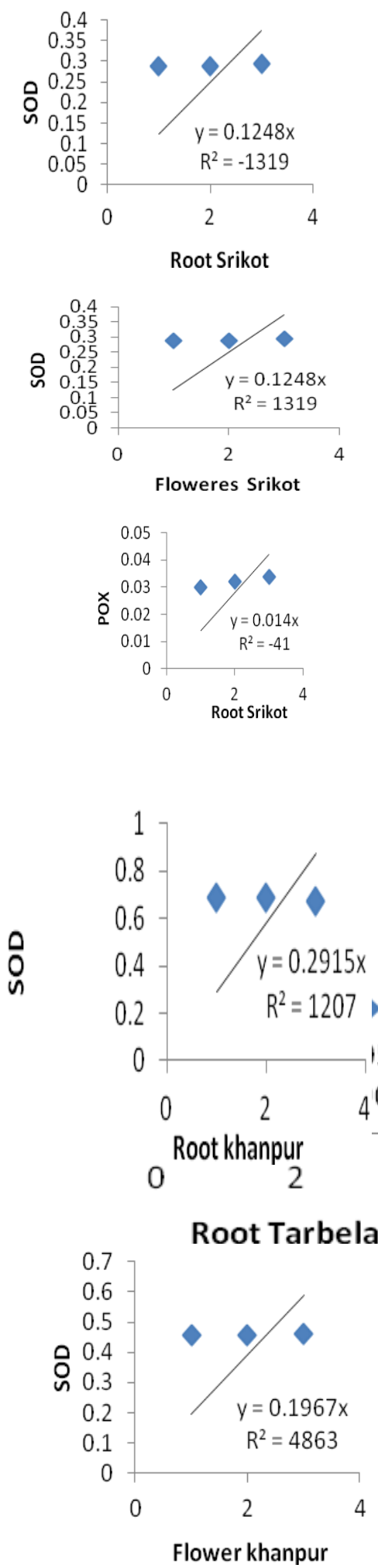
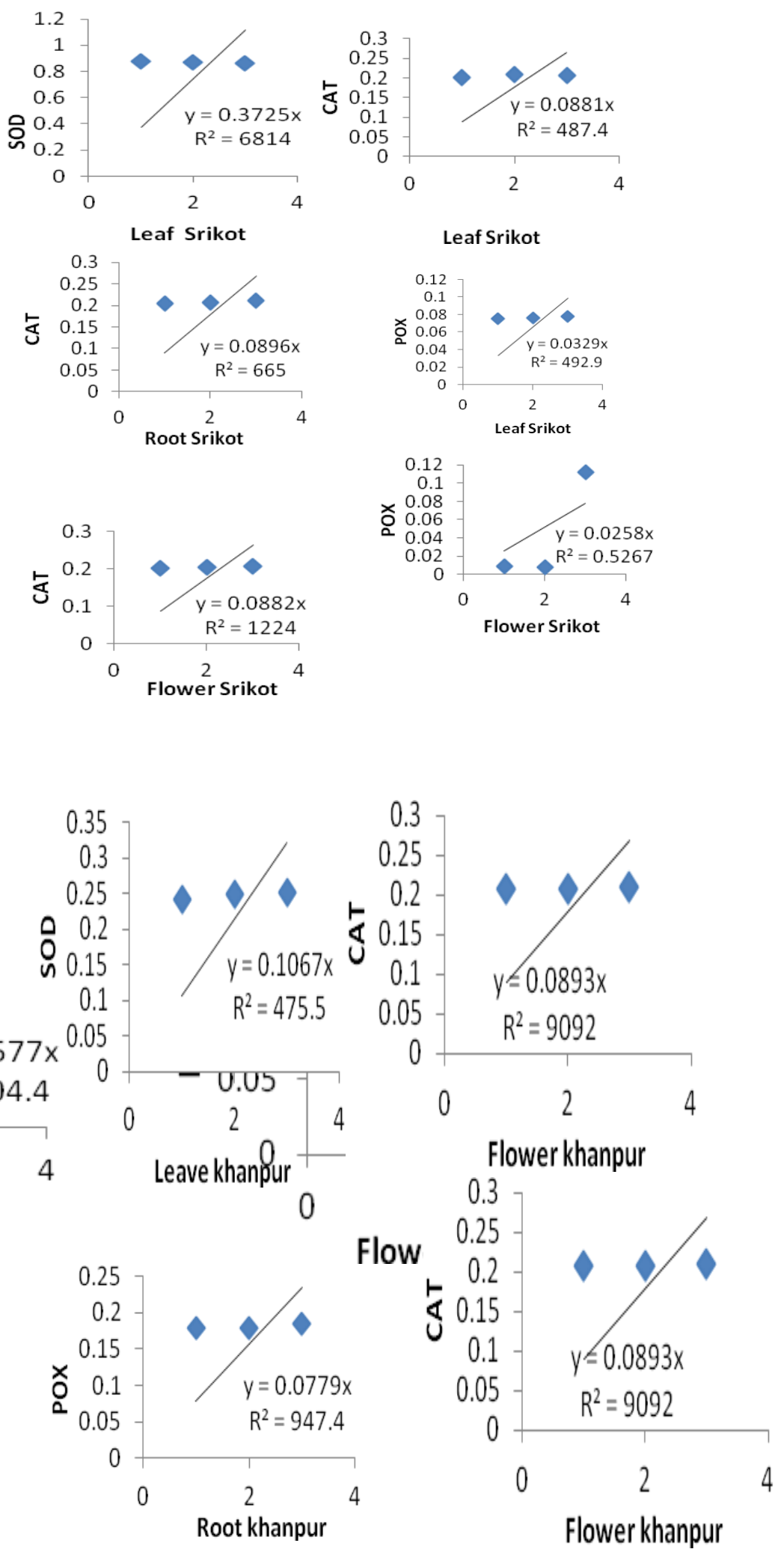


\section{Discussion}

Proximate analyses and ethnobotanical study of Fumaria indica from different locations to promote this medicinal plant. Medicinally the plants have countless significance. Its part is utilized to prevent vomiting, Fever and diabetes. Fumaria indica is rare plant a precise exploration has been performed so that's why peoples are unaware of plant importance. Ethnobotanical study is very important for plant medicinal value and knows information for traditional used of medicinal plant that's used for the treatments of different diseases. Pakistan is the homeland of different medicinal plant people used native plants in their daily routine life for medicinal purposes (Ahmad and Husain, 2008). Fresh weight of Fumaria indica was measured from different locations results were found that more fresh weight is obtained Tarbela plant (5.72g) compare to City (5.56) Khanpur (5.53g) and Srikot (5.51g) fresh plant weight shown Figure 11. The difference occurred due to biotic factor that influence the plant. Analyzed the dry weight of Fumaria indica from different locations from which more dry weight quantity was measured $(1.28 \mathrm{~g})$ from City plant than that of Srikot (1.25g) Tarbela (1.24g) and Khanpur (1.22g) shown Figure:12.The difference occurred due to moisture contents which was present in plant. . Ash content of Fumaria indica was observed from different locations the result was obtained the higher ash content $(0.52 \%)$ from Khanpur area plant compare to Srikot $(0.48 \%)$ Tarbela $(0.45 \%)$ and City $(0.43 \%)$ shown Figure:13.This is similar to the finding of ( $\mathrm{Fu}$ et al., 2016).investigated that Ash content were different in different plant found that there is a negative response of ash with organic matter and both have an inverse relationship. They reported that increase in ash content decreased the organic matter content.

It was found that crude fiber content were analyzed in different parts of Fumaria indica at different locations (Srikot, Khanpur, City, Tarbela). The higher content (16.1mg) was obtained in leaves of City and the lower crude fiber content $(5.5 \mathrm{mg}$ ) was measured in flower of Khanpur area plant and locations wise result were show that from hilly areas crude fiber contents were found higher in samples collected from Srikot as compare to Khanpur site plant samples on the other hand from plane areas higher crude fiber contents were found in City site sample as compare to Tarbela site samples shown Figure:14. This is similar to the finding of (Ravikhanthe, 2014) studied nutritional chemical constituents of the Fumaria indica. They isolated that $F$. indica contain huge amount of chemical constituent such as crude fiber, protein, fat, which was highly medicinal 
value.pH value were found in different parts Fumaria indica from different localities (Srikot, Khanpur, City, Tarbela) The higher $\mathrm{pH}$ value was show in (9.1) in leaf of Tarbela and the least $\mathrm{pH}$ value (6.58) in flower of Srikot and locations wise result were show that from hilly areas pH value were found higher in Srikot plant as compare to Khanpur area plant samples on the other hand from plane areas higher $\mathrm{pH}$ value was found in Tarbela plant as compare to City area plant samples shown Figure:15. The collection of plant samples in various places of Haripur due to different places soil $\mathrm{pH}$ effect the plant parts that's why the $\mathrm{pH}$ values or extract values the $\mathrm{pH}$ is changes. This observation is relevant to plants.(Laleh et al., 2006) who reported that the $\mathrm{pH}$ values depends on the different compounds which present in plants the variations in abiotic conditions during field and the factors effecting on plants $\mathrm{pH}$, temperature and soil condition etc. Ethnobotanical study of Fumaria indica were found from different locations (Srikot, Khanpur, City, Tarbela) in local language Fumaria indica was called 'Papra" finding that Fumaria indica has highly medicinal value plants were connected through stomach disorders follow by those related with reproductive, respiratory, cleansing of blood, skin allergies, brain and nerves, urinary, nutritional and tonic, and use to relief the bones and joints pain. Plant was used by local community as whole plant, leave, root and flower these all part were highly medicinal used for the treatment of diseases, utilized in the form of powder, decoction, tea, paste, fresh, juice, cream and Tincher shown in Figure. 16-19. which is closest to (Ravikhanthe, 2014) investigated that Fumaria indica \& Caesalpinia bonducella are the plants known for their digestive, spasmolytic, diuretic, anthelmintic, hepatoprotective, anti-inflammatory, antipyretic anti dysentery activity.Powder drugs of (leaves, roots and flowers) of Fumaria indica were made for different analyses.

Conclution: Fumaria indica \& Caesalpinia bonducella are the plants known for their digestive, spasmolytic, diuretic, anthelmintic, hepatoprotective, anti-inflammatory, antipyretic anti dysentery activity.Powder drugs of (leaves, roots and flowers) of Fumaria indica were made for different analyses.

\section{Declarations}

Ethics approval and consent to participate

Not applicable.

\section{Consent for publication}


Not applicable.

\section{Availability of data and materials}

Data sharing not applicable to this article as no datasets were generated or analysed during the current study.

\section{Funding}

No funding supported this study.

\section{Competing interests}

Conflict of interest no potential conflict of interest reported.

\section{Authors' contributions}

Lubna conduted the whole study .gulam mujtaba supervised the study, Nadia helped in data Collection.saira bibi and fiaz khan prepare and formate the manuscript, masued and waseem co supervoised the research.

\section{Acknowledgments}

I would like to acknowledge my supervising team and my coauthors.

Ahmad, S. S. and Husain, S. Z. (2008) Ethno medicinal survey of plants from salt range (Kallar Kahar) of Pakistan. Pak. J. Bot, 40(3): 1005-1011. 
Canales, M., Hernández, T., Caballero, J., De Vivar, A. R., Avila, G., Duran, A. and Lira, R. (2005) Informant consensus factor and antibacterial activity of the medicinal plants used by the people of San Rafael Coxcatlán, Puebla, México. Journal of ethnopharmacology, 97(3): 429-439.

Fu, Q., Sanganyado, E., Ye, Q. and Gan, J. (2016) Meta-analysis of biosolid effects on persistence of triclosan and triclocarban in soil. Environmental Pollution, 210: 137-144.

Hussain, J., Khan, F. U., Ullah, R., Muhammad, Z., Rehman, N., Shinwari, Z. K., Khan, I. U., Zohaib, M., Din, I. and Hussain, S. M. (2011) Nutrient evaluation and elemental analysis of four selected medicinal plants of Khyber Pakhtoon Khwa, Pakistan. Pak. J. Bot, 43(1): 427-434.

Ilangovan, M., Guna, V., Hu, C., Nagananda, G. and Reddy, N. (2018) Curcuma longa L. plant residue as a source for natural cellulose fibers with antimicrobial activity. Industrial Crops and Products, 112: 556-560.

Jackson, R. F., Lichtenberg, F. V. and Otto, G. F. (1962) Occurrence of adult heartworms in the venae cavae of dogs. Journal of the American Veterinary Medical Association, 141(1): 117-121.

Khan, S., Al-Qurainy, F., Nadeem, M. and Tarroum, M. (2012) Development of genetic markers for Ochradenus arabicus (Resedaceae), an endemic medicinal plant of Saudi Arabia. Genet Mol Res, 11: 1300-1308.

Kumar, N., Kulsoom, M., Shukla, V., Kumar, D., Kumar, S., Tiwari, J. and Dwivedi, N. (2018) Profiling of heavy metal and pesticide residues in medicinal plants. Environmental Science and Pollution Research, 25(29): 29505-29510.

Mabberley, D. (1987) The plant book.- Cambridge. Cambridge Univ. Press, New York.

Maiza-Benabdesselam, F., Chibane, M., Madani, K., Max, H. and Adach, S. (2007) Determination of isoquinoline alkaloids contents in two Algerian species of Fumaria (Fumaria capreolata and Fumaria bastardi). African Journal of Biotechnology, 6(21).

Rao, A. Q., Bakhsh, A., Kiani, S., Shahzad, K., Shahid, A. A., Husnain, T. and Riazuddin, S. (2009) RETRACTED: The myth of plant transformation. Elsevier.

Rao, B. R. P. and Sunitha, S. (2011) Medicinal plant resources of Rudrakod sacred grove in Nallamalais, Andhra Pradesh, India. Journal of Biodiversity, 2(2): 75-89. 
Shah, H. and Khan, A. A. (2017) Phytochemical characterisation of an important medicinal plant, Chenopodium ambrosioides Linn. Natural product research, 31(19): 2321-2324.

Singh, R., Gangwar, S. P., Singh, D., Singh, R., Pandey, R. and Kalra, A. (2011) Medicinal plant Coleus forskohlii Briq.: disease and management. Medicinal Plants-International Journal of Phytomedicines and Related Industries, 3(1): 1-7. 


\section{Figures}

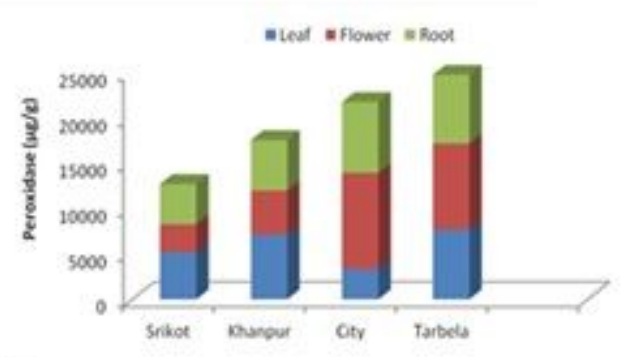

(a)

Dry weight

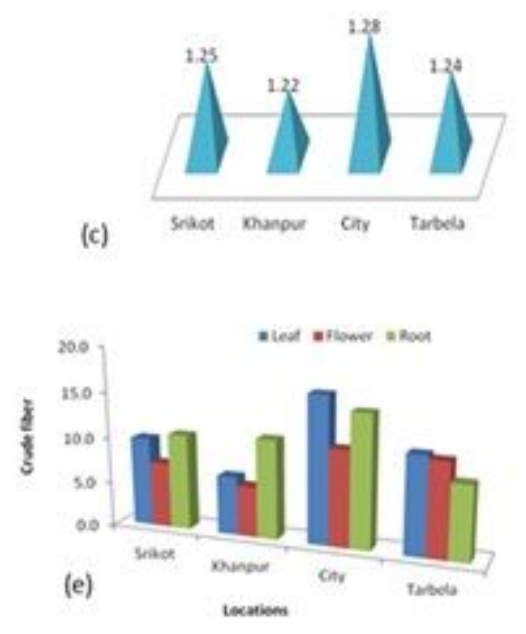

Fresh weight

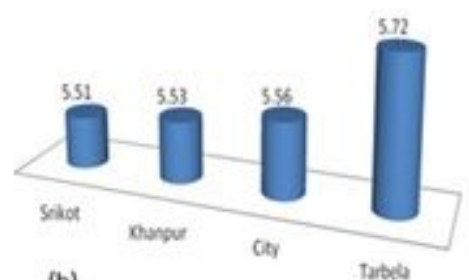

(b)
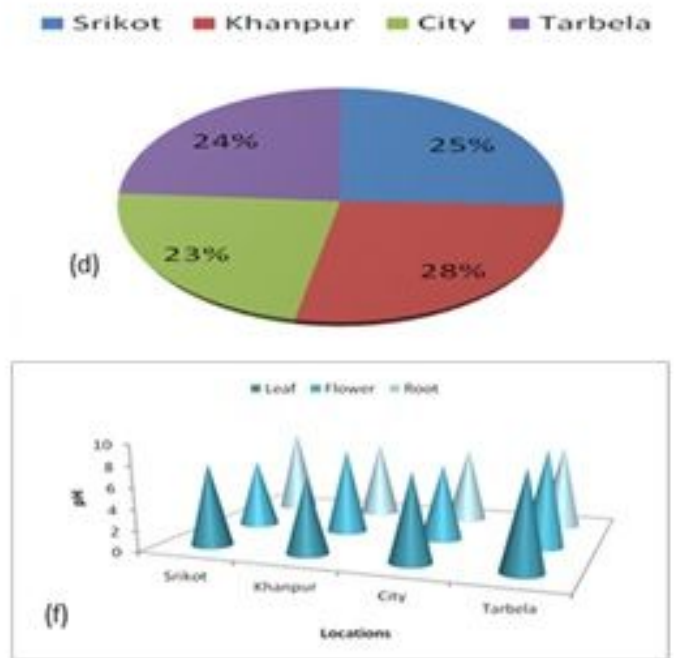

\section{Figure 1}

(a)The peroxidase contents Fumaria indica at different locationsFigure (b) Total fresh weight of Fumaria indica plant from different locationsFigure (c) Total dry weight of Fumaria indica plant from different locations. (d) The Ash content of Fumaria indica from different locations. $€$ Crude fiber contents of Fumaria indica at different locations. $(f)$ pH values of Fumaria indica in different parts of plant from different locations

Respondants

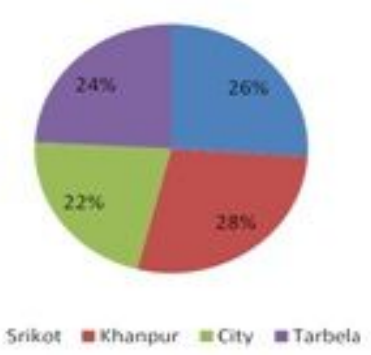

Figure 2

Percentage of respondent`s preferences for medicinal use of Fumaria indica at different locations. 


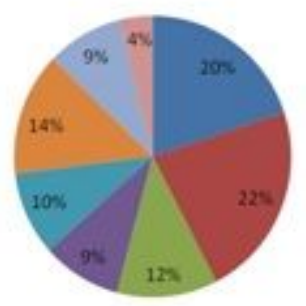

Digestion

- elood purification

eskin

=Urinarysystem

a Nutnition and tonic

- Bones and joint

= Reproduction

a Rispiration

\section{Figure 3}

Percentage of respondent's preferences for category of use, of Fumaria indica from all selected locations.

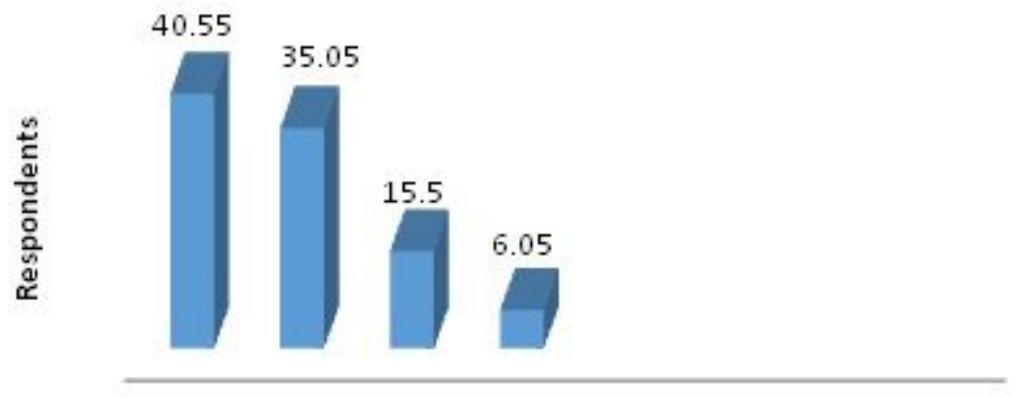

Whole Leave Root Flower plant

Medicinal importance plant parts of Fumaria indica

\section{Figure 4}

Percentage of respondent`s preference part used of Fumaria indica at different locations.

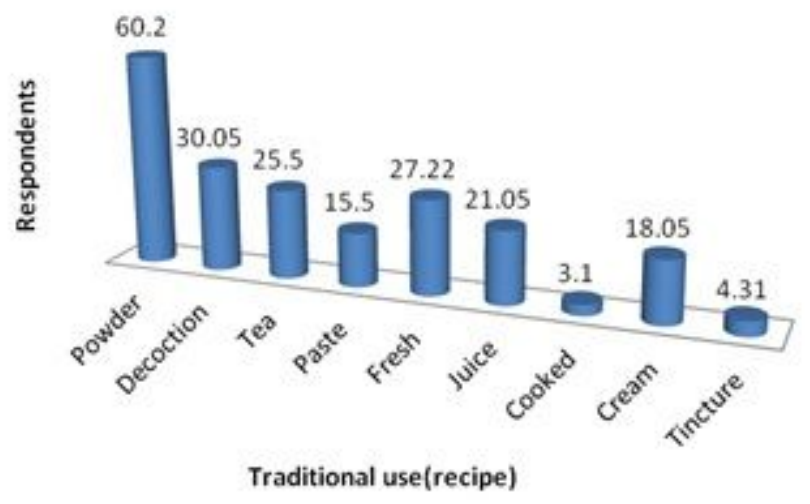

Figure 5

Percentage of respondent`s preference for traditional use (recipe) of Fumaria indica at different locations. 